\title{
Thermal Stability and Effect of Heat Treatment on Manganese Doped Silica Borotellurite Glass
}

\author{
I. Zaitizila, M. K. Halimah*, F. D. Muhammad, M. F. Faznny \\ Glass and Dielectric Lab, Department of Physics, Faculty of Science, University Putra Malaysia, Serdang, Malaysia \\ Email: zaitizila@yahoo.com, ^hmk6360@gmail.com, farahdiana@upm.edu.my,fazn nymf@gmail.com
}

How to cite this paper: Zaitizila, I., Halimah, M.K., Muhammad, F.D. and Faznny, M.F. (2018) Thermal Stability and Effect of Heat Treatment on Manganese Doped Silica Borotellurite Glass. Journal of Materials Science and Chemical Engineering, 6, 24-30.

https://doi.org/10.4236/msce.2018.64004

Received: March 9, 2018

Accepted: April 5, 2018

Published: April 12, 2018

\begin{abstract}
Glasses with chemical formula of $\left\{\left[\left(\mathrm{TeO}_{2}\right)_{0.7}\left(\mathrm{~B}_{2} \mathrm{O}_{3}\right)_{0.3}\right]_{0.8}\left[\mathrm{SiO}_{2}\right]_{0.2}\right\}_{1-\mathrm{x}}\left\{\mathrm{MnO}_{2}\right\}_{\mathrm{x}}$ where $\mathrm{x}=0.00 \leq \mathrm{x} \leq 0.05$ molar fraction were fabricated using melt quenching technique. The temperature used in the heat treatment process of the glass sample is $600^{\circ} \mathrm{C}$. Calorimetric measurement had been carried out to study the thermal properties of the fabricated glass. The crystallization kinetics of the glass system we reexamined under non-isothermal conditions via differential scanning calorimetric (DSC). The glass transition ( $\mathrm{Tg}$ ), onset glass transition (To), maximum crystallization temperature (Tc) and melting temperature (Tm) were determined. Results from DSC proved that the studied glasses have good thermal stability (Ts) in which indicates its high resistance to devitrification. Strong indicator for the glass forming ability of a glass material, Hurby parameter $(\mathrm{Kgl})$ was also calculated in this research.
\end{abstract}

\section{Keywords}

Manganese, Thermal Stability, DSC, Heat Treatment

\section{Introduction}

Tellurium oxide $\left(\mathrm{TeO}_{2}\right)$ based glasses are promising material and exclusively suitable for electro-optic fibre, optical switching devices and laser hosts [1] [2]. According to Stanworth and Nasu et al., tellurite possess large refractive index, low softening points, large thermal expansion, excellent infrared transmittance, high dielectric constant and good chemical durability [3] [4]. The calorimetry is a process of measuring the amount of heat released or absorbed with the surroundings and usually used for detecting chemical reactions, physical changes or phase transitions. In calorimetry, by knowing the changes in heat, one can determine whether or not a reaction is exothermic or endothermic which either 
release heat or absorb heat. Usually, calorimeters are used in the field of material science, chemistry, physics and biology. Recently, calorimeters are utilized in nanoscience field to measure thermodynamic properties of the biomolecules and nano-sized materials [5]. The differential scanning calorimetry (DSC) is one of the thermal analytical techniques that measure a sample material relative to a reference. The DSC measurement can be classified into two methods, heat flux DSC or power compensation DSC which give the information on the kinetic of first order phase transformation. DSC is one of the popular methods because it is cost-effective and only requires simple sample preparation steps. Other than that, thermal transition gives information on the temperature, moisture content in material and time dependent changes in amorphous material during drying and storage [6]. The aims of this study are to study the thermal properties and the effect of heat treatment on silica borotellurite glass doped with manganese oxide.

\section{Methodology}

The ternary glass samples with the composition of $\left\{\left[\left(\mathrm{TeO}_{2}\right)_{0.7}\left(\mathrm{~B}_{2} \mathrm{O}_{3}\right)_{0.3}\right]_{0.8}\left[\mathrm{SiO}_{2}\right]_{0.2}\right\}_{1-\mathrm{x}}\left\{\mathrm{MnO}_{2}\right\}_{\mathrm{x}}$ were prepared through melt-quenching methods by mixing specific weights of tellurium oxide (Alfa Aesar, 99.99\%), boron oxide (Alfa Aesar, 98.5\%), rice husk ash as silica source (98.85\%) and manganese (IV) oxide (Alfa Aesar, 99.99\%). The $\mathrm{x}$ in the chemical formula represents $0.00,0.01,0.02,0.03,0.04$ and 0.05 molar fraction of manganese oxide. All the chemical powders were mixed together in an alumina crucible for 30 minutes before transferred to first furnace at $400^{\circ} \mathrm{C}$ for pre-heating process. Then, the crucible was transferred to second furnace at $1100^{\circ} \mathrm{C}$ for a period of three hours for melting process. The melt was then quenched into a cylindrical-shaped stainless steel split mould which has been preheated beforehand at $400^{\circ} \mathrm{C}$. Next, the quenched glass was sent to be annealed at the first furnace at $400^{\circ} \mathrm{C}$ for two hours. The furnace was turned off and the sample was left in the furnace to be cooled to room temperature. The fabricated glass samples were then heat-treated at $600^{\circ} \mathrm{C}$ for three hours. The glass transition temperature ( Tg), onset glass temperature (To), crystallization temperature ( $\mathrm{Tc}$ ) and melting point temperature $(\mathrm{Tm})$ were determined by using differential scanning calorimetry (Thermo Gravitmetric Analyzer, $1 \mathrm{HT}$ ) at a heating rate of $10^{\circ} \mathrm{C} / \mathrm{min}$ from room temperature to $1200^{\circ} \mathrm{C}$. The temperature precision of the equipment is $\pm 0.1 \mathrm{~K}$.

\section{Result and Discussion}

In order to understand phase transformation in glass system, the glass samples were tested by employing non-isothermal techniquein which the samples were heated at a fixed rate and the heat evolved was recorded as function of temperature or time. The DSC data that had been recorded with the respect of different temperature of glasses and concentration of manganese are presented in Figure 1 and Figure 2. 


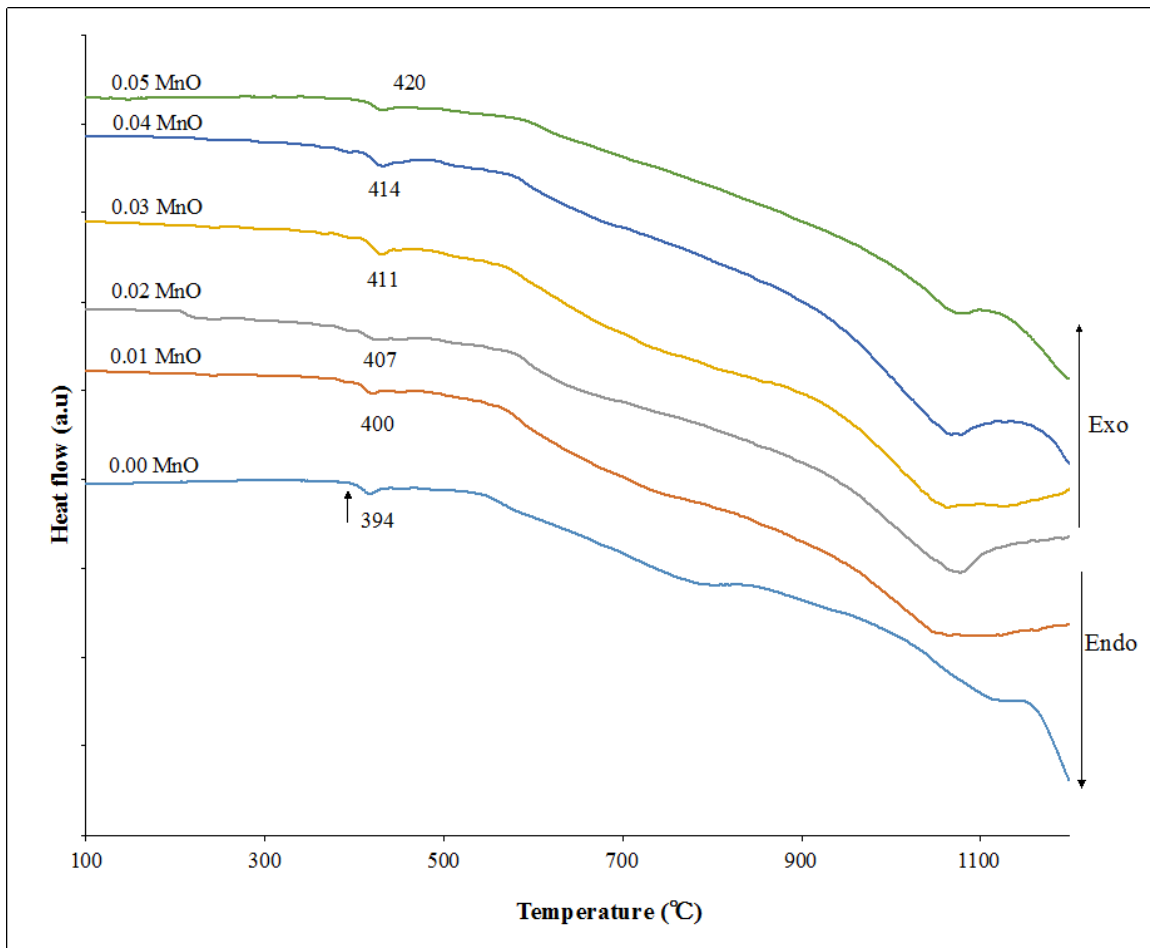

Figure 1. DSC curve foruntreated glass sample at room temperature.

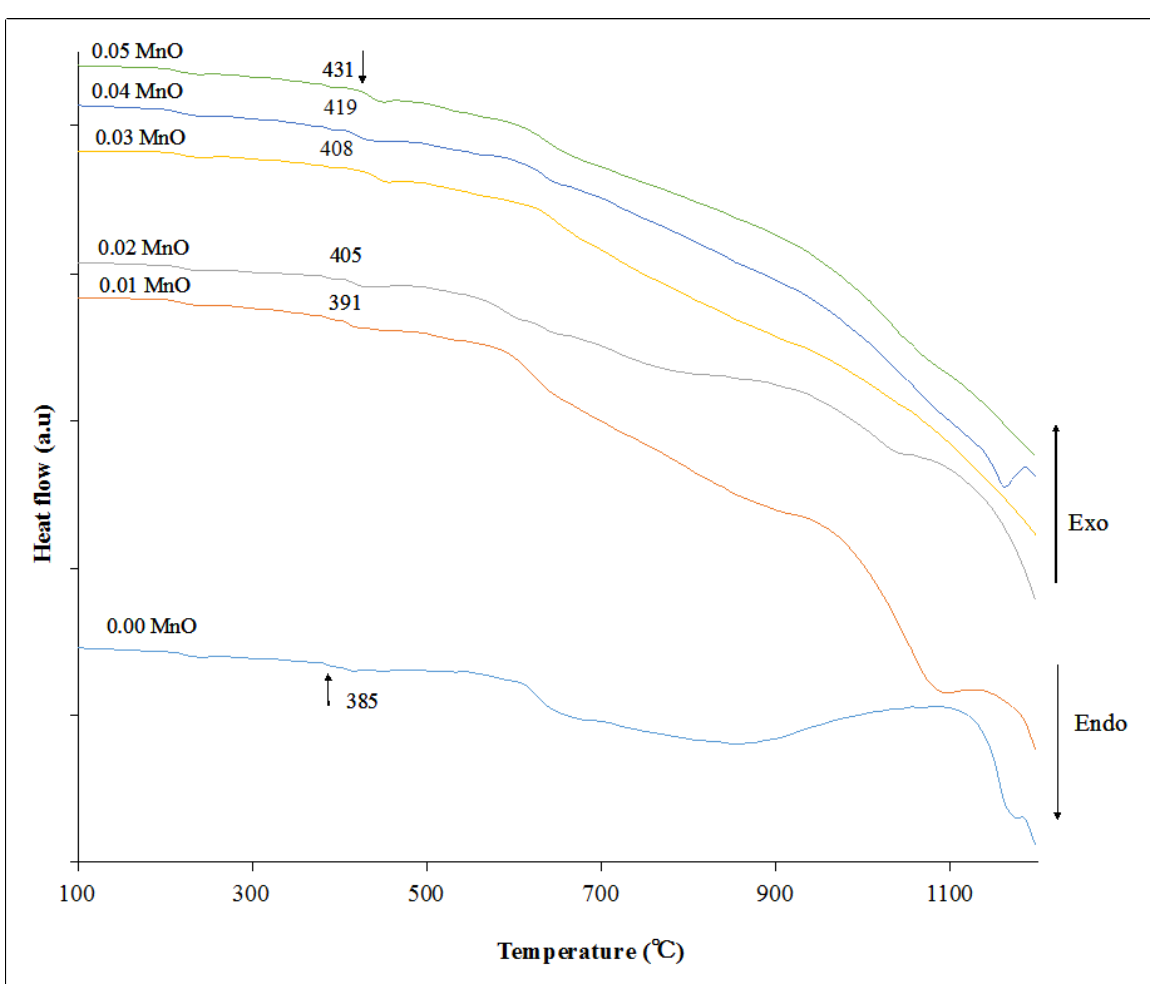

Figure 2. DSC curve for heat-treated glass sample.

Figure 1 and Figure 2 show the DSC curves that had been recorded in the temperature ranging from $100^{\circ} \mathrm{C}$ to $1200^{\circ} \mathrm{C}$. Based on Figure 1, the endothermic 
peaks observed at temperature ranging from $394^{\circ} \mathrm{C}$ to $420^{\circ} \mathrm{C}$ are due to the glass transition temperature $(\mathrm{Tg})$ while exothermic peaks present in the range between $542^{\circ} \mathrm{C}$ to $606^{\circ} \mathrm{C}$ are because of the crystallization temperature (Tc). Figure 1 also reveals the melting point $(\mathrm{Tm})$ and onset crystallization (To) that located in the ranges of $1059^{\circ} \mathrm{C}$ to $1118^{\circ} \mathrm{C}$ as well as $495^{\circ} \mathrm{C}$ to $546^{\circ} \mathrm{C}$ respectively. From Figure 2, after the samples were heat treated at $600^{\circ} \mathrm{C}$ for 3 hours, the DSC curves of phase transformation for all glass sample show an increment of temperature in every parameter of the glass samples. Glass transition temperature $(\mathrm{Tg})$ of the heat treated glass ranges between $385^{\circ} \mathrm{C}$ to $431^{\circ} \mathrm{C}$ while melting temperature $(\mathrm{Tm})$ are now in the range of $1085^{\circ} \mathrm{C}$ and $1168^{\circ} \mathrm{C}$. The onset crystallization temperature (To) of the studied samples can be observed in the range between $581^{\circ} \mathrm{C}$ and $647^{\circ} \mathrm{C}$ while crystallization temperature are situated in the range of $604^{\circ} \mathrm{C}$ to $675^{\circ} \mathrm{C}$.

As the concentration of the dopant increases for both sample at room temperature and $600^{\circ} \mathrm{C}$, Tgvalues tend to rise and it records the highest Tgin sample with 0.05 molar fraction of $\mathrm{Mn}$. According to previous research, the appearance of single peak Tgindicates the high homogeneity and relatively high glass forming abilities of the glass samples [7]. The undoped glass sample shows the highest Tmvalue when compared to untreated and heat-treated glass samples because of the high concentration of silicain undoped glass sample among other glass composition. Crystallization can be defined as the solidification of atoms or molecules to become a highly organized structure known as crystal. Based on Figure 1 and Figure 2, Tcvalue increases with increasing manganese content. The increment of Tc values proved that the incorporation of manganese in glass system tend to increase the temperature of crystallization since manganese plays the role of network modifier in the glass system [8]. After the heat treatment procedure, Tc increases about $69^{\circ} \mathrm{C}$ due to the increment in the expansion coefficient of the resulting glass-ceramics [8].

Thermal stability (Ts) was first introduced by Dietzel [9] with formula of Ts = To - Tg. From this characteristic temperatures, Hruby introduced the glass forming ability, $\mathrm{Kgl}$ which can be calculated by utilizing the relation, $\mathrm{Kgl}=\mathrm{Tc}-$ $\mathrm{Tg} / \mathrm{Tm}-\mathrm{Tc}[10]$. Another parameter that is usually used to estimate the glass thermal stability with the formula of $\Delta \mathrm{T}=(\mathrm{Tc}-\mathrm{To})(\mathrm{To}-\mathrm{Tg}) / \mathrm{Tg}$ was introduced by Saad and Poulin [11]. $\Delta \mathrm{T}$ reflects the resistance of the glass to devitrification after glass formation process in which (Tc - To) term in the equation is related to the rate of divitrification transformation of the glassy phase.

Ts values for untreated and heat-treated glass sample ranges from $101^{\circ} \mathrm{C}$ to $126^{\circ} \mathrm{C}$ and $196^{\circ} \mathrm{C}$ to $216^{\circ} \mathrm{C}$ respectively as a manganese content rises. Increasing Tsvalues suggest the high thermal stability and high kinetic resistance of the glass system against crystallization as well as the ability of the sample to retard nucleation process. Glass with the highest manganese content has the highest thermal stability which implies that manganese tends to block the glass structure from crystallizing [12]. After heat treatment process, the increasing Tsvalue makes the glass system become stable and stronger [13]. 


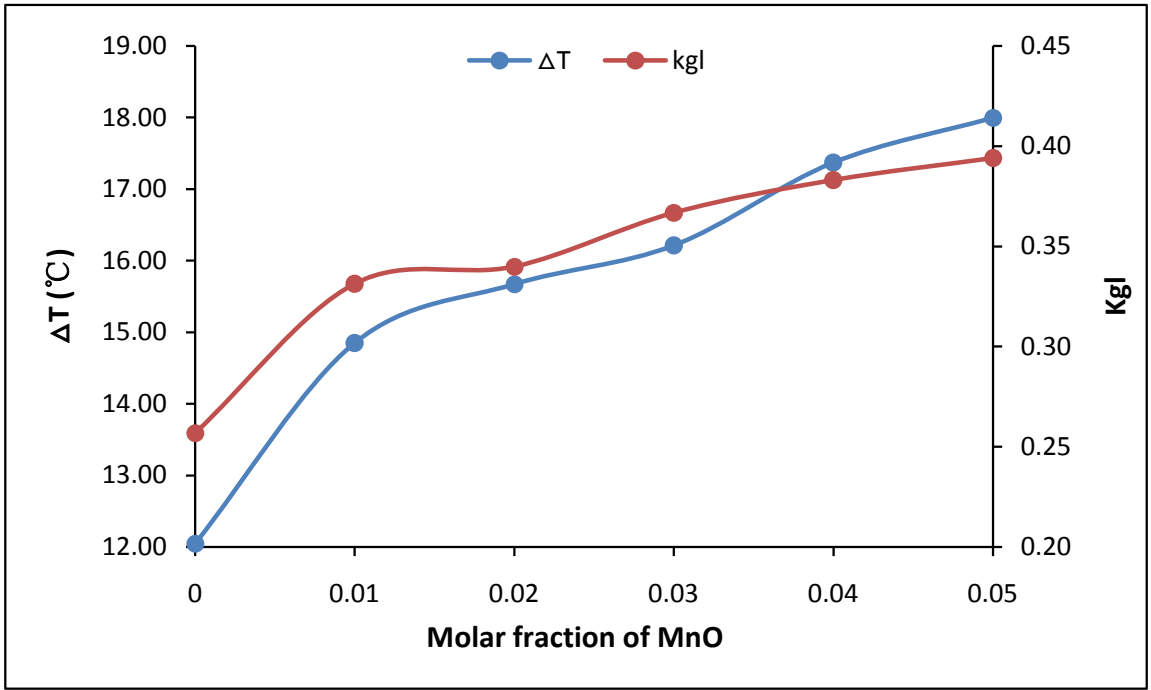

Figure 3. The composition dependence thermal stability $(\Delta \mathrm{T})$ and Hurby number $\left(\mathrm{K}_{\mathrm{gl}}\right)$ for untreated glass sample.

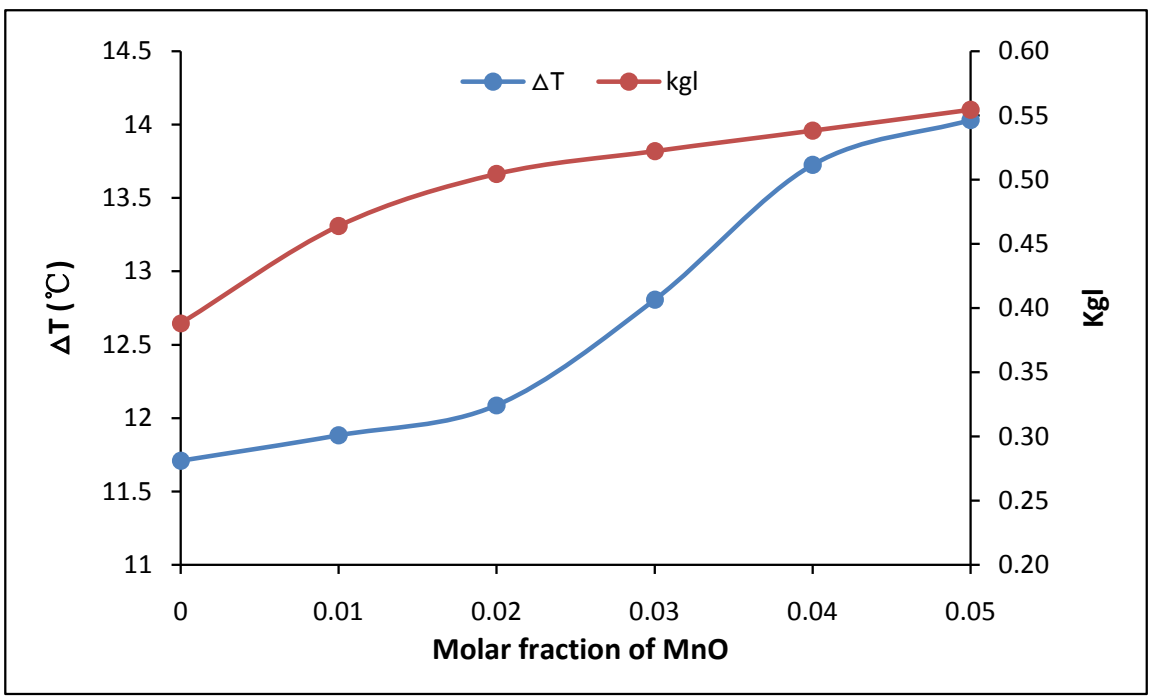

Figure 4. The composition dependence thermal stability $(\Delta \mathrm{T})$ and Hurby number $\left(\mathrm{K}_{\mathrm{gl}}\right)$ for heat-treated glass sample.

On the other hand, Hurby parameter for both untreated and heat-treated glass have increasing trend with values in the range of 0.26 to 0.39 and 0.39 to 0.56 as shown in Figure 3 and Figure 4. In this study, the heating rate for all glass samples was kept constant at $10^{\circ} \mathrm{C} / \mathrm{min}$. According to previous research Fayek and Fadel, material with higher value of Tc-Tgable to delay its nucleation process while material with small $\mathrm{Tm}$-Tcvalue will able to retard the growth process [14]. Both untreated and heat-treated glass sample with $\mathrm{Kgl}$ values more than 0.1 proved that glass samples are stable and easy to form a glass [15].

Based on Figure 3 and Figure 4, the thermal stability for untreated glass sample has a value ranging from $12.05^{\circ} \mathrm{C}$ to $18.0^{\circ} \mathrm{C}$ while those of heat-treated glass sample has a values ranging in 11.71 and 14.03. $\Delta \mathrm{T}$ recorded the highest valuein- 
silica borotellurite glass with the highest concentration of manganese. This has verified the ability of manganese to increases the resistance to devitrification after it was added into glass system. Moreover, high value of (To - Tg) usually linked to the delays in nucleation process [16]. In short, the glass samples become more thermally stable as the concentration of manganese in silica borotellurite glass increases.

\section{Conclusion}

Thermal properties for glass series with chemical composition of $\left\{\left[\left(\mathrm{TeO}_{2}\right)_{0.7}\left(\mathrm{~B}_{2} \mathrm{O}_{3}\right)_{0.3}\right]_{0.8}\left[\mathrm{SiO}_{2}\right]_{0.2}\right\}_{1-\mathrm{x}}\left\{\mathrm{MnO}_{2}\right\}_{\mathrm{x}}$ where $\mathrm{x}$ varies from 0.0 until 0.05 molar fraction had been studied via non-isothermal DSC measurement. From the data retrieved and calculated, manganese content and the heat treatment procedure did influence and improve the thermal properties of the glass system. The glass sample with the highest manganese content has the highest thermal stability and lowest crystallization ability. The heat treatment process also helped in changing the structure and rigidity of the glass as seen in the values for $\mathrm{Tg}, \mathrm{Tc}$, Tm and To.

\section{Acknowledgements}

Authors are thankful to University Putra Malaysia (UPM) through GP-IPS (grant number: 9504400) for providing financial support.

\section{References}

[1] Ammar, A.A., El-Mallwany, R.A. and El-Zaidia, M.M. (1985) Infra-Red Spectra, Electronspin Resonance Spectra, and Density of $\left(\mathrm{TeO}_{2}\right)_{100-\mathrm{x}}-\left(\mathrm{WO}_{3}\right)_{\mathrm{x}}$ and $\left(\mathrm{TeO}_{2}\right)_{100-\mathrm{x}}-$ $\left(\mathrm{ZnCl}_{2}\right)_{\mathrm{x}}$ Glasses. Physica Status Solidi (A) Applied Research, 91, 637-642. https://doi.org/10.1002/pssa.2210910234

[2] Sidkey, M.A. and Gaafar, M.S. (2004) Ultrasonic Studies on Network Structure of Ternary $\mathrm{TeO}_{2}-\mathrm{WO}_{3}-\mathrm{K}_{2} \mathrm{O}$ Glass System. Physica B: Condensed Matter, 348, 46-55. https://doi.org/10.1016/j.physb.2003.11.005

[3] Stanworth, J.E. (1952) Tellurite Glasses. Nature, 169, 581-582. https://doi.org/10.1038/169581b0

[4] Nasu, H., Matsushita, O., Kamiya, K., Kobayashi, H. and Kubodera, K.I. (2000) Third Harmonic Generation from $\mathrm{Li}_{2} \mathrm{O}-\mathrm{TiO}_{2}-\mathrm{TeO}_{2}$ Glasses. Journal of Non-Crystalline Solids, 124, 275-277. https://doi.org/10.1016/0022-3093(90)90274-P

[5] Varghesea, N., Vivekchanda, S.R.C., Govindaraja, A. and Rao, C.N.R. (2008) A Calorimetric Investigation of the Assembly of Gold Nanorods to Form Necklaces. Chem Phys Lett, 450, 340-344. https://doi.org/10.1016/j.cplett.2007.11.022

[6] Roos, Y. and Karel, M. (1990) Differential Scanning Calorimetry Study of Phase Transitions Affecting the Quality of Dehydrated Materials. Biotechnology Progress, 6, 159-163. https://doi.org/10.1021/bp00002a011

[7] Reddy, P.V., Kanth, C.L., Kumar, V.P., Veeraiah, N. and Kistaiah, P. (2005) Optical and Thermoluminescence Properties of $\mathrm{R}_{2} \mathrm{O}-\mathrm{RF}-\mathrm{B}_{2} \mathrm{O}_{3}$ Glass Systems Doped with MnO. Journal of Non-Crystalline Solids, 351, 3752-3759.

https://doi.org/10.1016/j.jnoncrysol.2005.08.039 
[8] Abo-Mosallam, H.A., Darwish, H. and Salman, S.M. (2010) Crystallization Characteristic and Properties of Some Zinc Containing Soda Lime Silicate Glasses. Journal of Materials Science: Materials in Electronics, 21, 889-896.

https://doi.org/10.1007/s10854-009-0012-3

[9] Dietzel (1968) Glass Structure and Properties. Glasstech. Ber., 22, 1187.

[10] Hrubý, A. (1972) Evaluation of Glass-Forming Tendency by Means of DTA. Czechoslovak Journal of Physics, 22, 1187-1193. https://doi.org/10.1007/BF01690134

[11] Saad, M. and Poulin, M. (1987) Glass Forming Ability Criterion. Materials Science Forum, 19, 11-18. https://doi.org/10.4028/www.scientific.net/MSF.19-20.11

[12] Pascuta, P., Bosca, M., Borodi, G. and Culea, E. (2011) Thermal, Structural and Magnetic Properties of Some Zinc Phosphate Glasses Doped with Manganese Ions. Journal of Alloys and Compounds, 509, 4314-4319. https://doi.org/10.1016/j.jallcom.2011.01.056

[13] Durga, D.K. and Veeraiah, N. (2002) Physical Properties of $\mathrm{ZnF}_{2}-\mathrm{As}_{2} \mathrm{O}_{3}-\mathrm{TeO}_{2}$ Glasses Doped with $\mathrm{Cr}^{3+}$ Ions. Physica B: Condensed Matter, 324, 127-141. https://doi.org/10.1016/S0921-4526(02)01286-3

[14] Fayek, S.A. and Fade, M. (2009) Crystallization Kinetics for Sb Added to GeSe Chalcogenide Glass. Journal of Non-Oxide Glasses, 239-246.

[15] Murugan, G.S. and Ohishi, Y. (2004) $\mathrm{TeO}_{2}-\mathrm{BaO}-\mathrm{SrO}-\mathrm{Nb}_{2} \mathrm{O}_{5}$ Glasses : A New Glass System for Waveguide Devices Applications. Journal of Non-Crystalline Solids, 341, 86-92. https://doi.org/10.1016/j.jnoncrysol.2004.04.006

[16] Mehta, N., Tiwari, R.S. and Kumar, A. (2006) Glass Forming Ability and Thermal Stability of sOme Se-Sb Glassy Alloys. Materials Research Bulletin, 41, 1664-1672. https://doi.org/10.1016/j.materresbull.2006.02.024 